\title{
From molecular modules to modular materials*
}

\author{
Shaoqin Liu' ${ }^{1}$, Dirk Volkmer², and Dirk G. Kurth ${ }^{1,3, \neq}$ \\ ${ }^{1}$ Max Planck Institute of Colloids and Interfaces, D-14424 Potsdam, Germany; \\ 2University of Bielefeld, Faculty of Chemistry, P.O. Box 100 131, AC1 D-33501 \\ Bielefeld, Germany; ${ }^{3}$ National Institute for Materials Science (NIMS) 1-1 Namiki, \\ Tsukuba, Ibaraki 305-0044, Japan
}

\begin{abstract}
The combination of metallosupramolecular modules (MEMOs) as functional and amphiphiles as structural components is presented in detail to illustrate our current understanding of encapsulation using surfactants, lipids, and dendrimers. The simplicity of fabrication and the availability of the starting components allow this technique as an attractive tool to create new nanoscale molecular materials. The interaction of amphiphiles and MEMOs occurs spontaneously and is driven by the release of counterions as well as electrostatic and hydrophobic interactions.
\end{abstract}

\section{INTRODUCTION}

Nature repeatedly demonstrates exquisite control over the intramolecular forces that underlie the very existence of life, ranging from the molecular level, as in DNA, to the macroscopic length scale, as in bone or wood. As a result, natural materials are intrinsically hierarchical, which is often responsible for some of the unusual properties such as mechanical strength and toughness. Moreover, natural materials often comprise several functions. The cytoskeleton, for instance, determines cell and tissue shape, but also influences a wide range of fundamental cellular functions, such as migration, movement of organelles, and cell division. Due to the weak and competitive interactions, biological systems are responsive to external stimuli, that is, they can adapt their structure and function. Responsiveness is also a prerequisite for information signaling and transduction. Perhaps the most intriguing aspect of biological systems is their ability to self-repair and self-replicate. Inspired by nature, the selective introduction of specific molecular interactions to guide the association of functional modules is an overarching theme in current nanoscale materials and device design [1]. The technological and functional advantages of using nanoscaled or molecular components in a variety of devices have been recognized for some time now [2]. However, the formation of functional nanoscaled or molecular devices from nonbiological components or modules began only recently.

The methodologies used to create devices at the nanometer scale can be roughly categorized as those using lithography (top down) or self-assembly (bottom up). Certainly, self-assembly is claimed to be an important avenue toward the manufacture of the next-generation nanoscale molecular materials [3]. The particular advantages of this approach include parallel fabrication, (molecular) dimension control, component alignment, and repair mechanisms. The current challenge in the field of self-assembling supramolecular nanostructures is, therefore, to develop strategies to deliberately combine, orient, and order structural and functional modules in predictable ways because material and device performance is critically dependent on the spatial arrangements of the functional modules. In order to support, handle, manipulate, and operate devices at the nanoscopic length scale, it will also be advantageous to col-

\footnotetext{
*Plenary lecture presented at the $28^{\text {th }}$ International Conference on Solution Chemistry, Debrecen, Hungary, 23-28 August 2003. Other presentations are published in this issue, pp. 1809-1919.

‡Corresponding author: Tel: +49 (0)331-567 9211; Fax: +49 (0)331-567 9202; E-mail: kurth@ mpikg-golm.mpg.de
} 
lect and arrange the components in surface-confined structures, however, until now there are no generic methodologies available to achieve this goal [4]. In the last few years, the development of new methodologies to construct molecular objects with nanoscopic dimensions capable of mesoscopic pattern formation has been at the focus of supramolecular science [5]. With the remarkable progress in self-assembly of molecular components into specific arrays and polymers, there are many other recent examples of supramolecular species that are proposed as potential components for nanoscopic devices. In particular, the combination of supramolecular modules (SUMOs) as functional and amphiphiles as structural components appears as an attractive route toward this goal. The interaction of amphiphiles and SUMOs occurs spontaneously and is driven by the release of counterions as well as electrostatic and hydrophobic interactions [6].

Amphiphilic self-assembly is by far the most fundamental mechanism for the construction of soft matter materials [7] because soft materials exhibit significant technological value, as in microfluidic devices, electrical nanodevices [8], gene therapeutics [9], prostheses [10], cellular engineering [11], and medical devices [12], as well as sensing, catalysis, and signal tranduction [13]. Supramolecular complexes of surfactants [14-28] and lipids [29] with polyelectrolytes show a well-defined nanostructure as well as interesting mechanical and dielectric properties. Such composite systems, containing biological or naturally polyelectrolytes, can be used as drug delievery systems [30], pH-switchable systems [31], and templates for directing the structure of polymer architectures [32]. The self-assembly of amphiphiles and SUMOs is a simple yet efficient way of producing melt-processable, soluble materials with properties that range from thermoplastic through elastomeric to thermosetting [33]. In addition, amphiphilic self-assembly offers a promising solution to a prevailing problem in supramolecular materials chemistry: The modularity of this approach provides extensive control of structure and function from molecular to macroscopic length scale. In addition, the use of modules provides an unsurpassed degree of synthetic simplicity, diversity, and flexibility. The ability to control the spatial arrangement of functional constituents is of critical importance with respect to the encoding of new (collective) properties and the exploitation of a material's potential. However, the potential lack of symmetrical invariance (e.g., crystallinity) in such devices and materials poses a serious challenge to structure determination by traditional diffraction methods, which is of prime importance for the understanding of accurate structure-property relationships. Further progress in this area will, therefore, call for interdisciplinary research programs that go beyond the classical approaches in chemistry, physics, and engineering.

\section{METALLOSUPRAMOLECULAR MODULES}

Metallosupramolecular modules (MEMOs) made by metal ion-directed self-assembly are of particular interest for the construction of technological devices [34-36]. They provide a set of well-defined coordination geometries, a range of binding strengths and ligand exchange kinetics that allow reversible assembly-disassembly of supramolecular architectures, including switchable interaction sites. In addition, they possess a variety of photochemical, electrochemical, and reactive properties that are relevant for functional devices. Metal ions collect and spatially direct the assembly of ligands according to predetermined coordination algorithms. The final properties can, therefore, be tailored through the judicious choice of steric and electronic ligand-metal ion interactions [37]. The occurrence of semi-occupied d-orbitals gives rise to some of the most prominent properties of MEMOs including strong absorption, high quantum yields, suitable excited state life times, luminescence, and tunable redoxstates. These features can be explored for optical nonlinearity [38] as well as photomediated charge separation [39] for artificial photosynthesis. The splitting of the d-orbitals in a ligand field of appropriate symmetry and strength can give rise to thermally or photoinduced spin transition and spin crossover phenomenon, the most intriguing one being light-induced excited spin-state trapping (LIESST) [40], reverse [41] and low-spin LIESST [42]. While photomediated charge separation in polynuclear complexes has been studied in terms of artificial photosynthesis, such systems are also interesting for information processing devices. 
Another promising class of MEMOs are polyoxometallates (POMs), well-defined, discrete nanoscopic clusters with a wide variety of applications in fundamental and applied science including catalysis [43], electrochemistry [44], electrooptics [45], and medicine [46]. In contrast to many semiconductor nanoparticles and quantum dots, POMs are transition-metal oxide clusters that are uniform at the atomic level with a broad range of structures and properties that form through sequential self-assembly of metal-oxygen building blocks (see Fig. 6). An attractive feature of POM clusters is the ability of the metal-oxygen framework to accommodate excess electrons [47]. The reduction is generally reversible and occurs with marginal structural rearrangement. The reduced POMs frequently display a deep blue color. The ability to accept electrons under alteration of the light-absorbing properties is perhaps the most promising effect for the construction of functional devices and materials. The extinction coefficient of the colored POM state is comparable to that of organic dyes, however, the photochemical stability of POMs is far superior to that of organic molecules. The reduction of the POM cluster results in accumulation of negative charge, which increases the basicity of the POM anion. The reduction process may, therefore, be accompanied by concomitant protonation and, as a result, the redox properties of POMs are markedly pH-sensitive. While through crystal engineering, extended 2- and 3-dimensional solid-state arrays may be constructed, the exploitation and the encoding of value-adding properties of POMs as functional components in advanced materials remains elusive, mainly due to the fact that these materials are obtained as crystalline solids that are hard to process. Due to the high lattice energies associated with crystallization, the occurrence of distinct supramolecular architectures, such as liquid-crystalline phases, are rarely observed [48].

Due to the numerous properties of MEMOs, one can envision a wide variety of potential applications that utilize photons, electrons, spin transitions, and recognition phenomena at the metal center or in the coordination sphere in order to store, handle, or process information. Integration of these functional modules in suitable device architectures is, therefore, an important and rewarding research opportunity.

\section{METALLOSUPRAMOLECULAR POLYELECTROLYTE-AMPHIPHILE COMPLEXES}

A facile entry to complex hierarchical architectures is based on a colloid-chemical approach by decorating metallo-units with amphiphiles [49-52]. First, metal-induced self-assembly with ditopic ligands, such as bisterpyridines, results in extended, one-dimensional metallosupramolecular polyelectrolytes (MEPEs). A linear, positively charged macromolecule is formed due to the octahedral coordination geometry around the metal center. Second, amphiphilic self-assembly of MEPE and an amphiphile, such as dihexadecyl phosphate (DHP), results in spontaneous formation of polyelectrolyte-amphiphile complexes (PACs). The composition of PAC-1 formed under the particular assembly conditions is such that six DHPs bind per repeat unit [53]. Presumably, DHPs form a charged hydrogen-bonded network, which binds to MEPE through electrostatic interactions as schematically depicted in Scheme 1. In contrast, the composition of PAC-2 and PAC-3 are such that two DHPs bind per repeat unit. The association of MEPE and DHP has a profound impact on the properties of the final material. PACs dissolve in common organic solvents and spread at the air-water interfaces, indicating that the amphiphiles effectively shield the hydrophilic portion of MEPE. We, therefore, assume that, in solution, the amphiphiles are predominately located around the hydrophilic metal-ion centers as depicted in Scheme 1. Different metal ions can be introduced in MEPE either deliberately or statistically. Coassembly with macromolecular receptors results in novel block copolymers. 


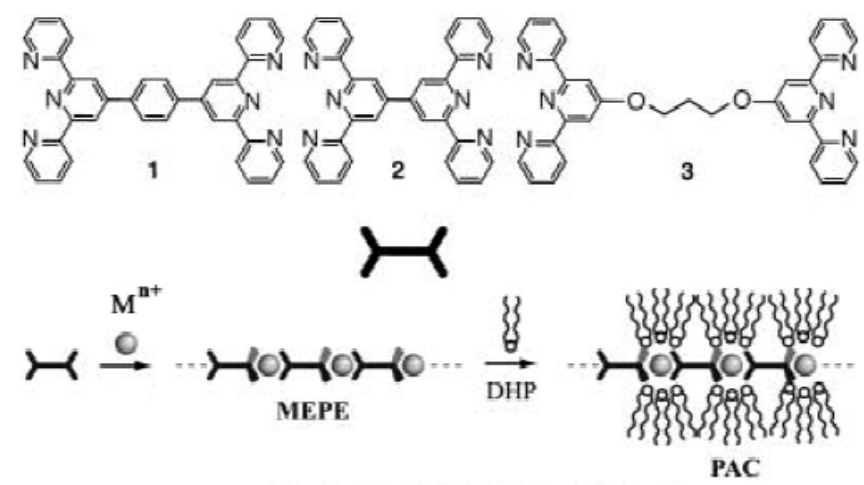

Scheme 1 Metal ion-induced self-assembly of ditopic modules results in metallosupramolecular polyelectrolytes (MEPEs). By assembling MEPE with amphiphiles, the corresponding polyelectrolyte-amphiphile complexes (PACs) are formed. Coassembly with macromolecular receptors results in novel block copolymers. Different metal ions can be introduced in the systems either statistically or deliberately. The structure and properties of these systems shall be explored in solution, lyo- and thermotropic mesophases, thin films, and nanostructures. The weak competing interactions that hold the components in place make these extended supramolecular assemblies ideal model systems to study the effect of external stimuli on macroscopic properties.

\section{Langmuir monolayer}

The Langmuir-Blodgett (LB) technique was one of the first methods to fabricate thin films with longrange order and precise thickness control and played a key role in the development of molecular electronics [54]. The defined conditions of the air-water interface permit us to explore the surface activity and provide molecular-level control to construct layered materials using LB film transfer. The general concept of Langmuir monolayer preparation and LB transfer is depicted as follows: A known amount of the sample is dissolved in a water-immiscible volatile solvent, and the solution is spread on the water surface contained within a Langmuir trough. Upon evaporation of the solvent, a monolayer remains at the air-water interface, which is subsequently compressed with a moving barrier, while the pressure is recorded. During compression, the surface pressure, $\pi$, is measured and displayed as a function of the corresponding area, $A$, revealing details of the phase behavior of the monolayer as well as information about the size of the molecules. Langmuir monolayers can be transferred on solid substrates by dipping an appropriate substrate through the interface at constant pressure. Repeated monolayer transfer generally yields highly ordered lamellar multilayers.

Spreading the preformed PAC-1 at the air-water interface results in a Langmuir monolayer (Fig. 1) [53]. The interaction between DHP and MEPE evoke an untitled hexagonal liquid-condensed phase of the aliphatic alkyl chains even at low surface pressure. The electrostatic coupling is thought to be responsible for the stability of the Langmuir monolayer and its high collapse pressure. In contrast to the Langmuir monolayer of neat DHP, the PAC-1 isotherm shows no distinct phase transition between the titled and untitled liquid-condensed phase, which is ascribed to the polycrystalline nature of the PAC-1 Langmuir monolayer. The structure of the PAC-1 Langmuir monolayer is rationalized as a stratified bilayer architecture as schematically depicted in Fig. 1. The amphiphilic molecules assemble into a closed packed monolayer (with occasional aggregates) on the water surface, while the MEPE is immersed in the aqueous subphase, electrostatically coupled to the DHP monolayer. The structural flexibility required to form this stratified architecture is provided by the noncovalent interactions within the PAC assembly. The driving force for the structural organization is provided by the prevailing surface tension across the air-water interface.

PAC monolayers are readily transferred onto solid substrates with the LB technique [49]. In the case of PAC-1, the average thickness per layer is $2.8 \pm 0.2 \mathrm{~nm}$, corresponding to a monolayer. Repeated transfer leads to a LB multilayer. X-ray reflectance shows both Kiessig fringes as well as Bragg peaks 

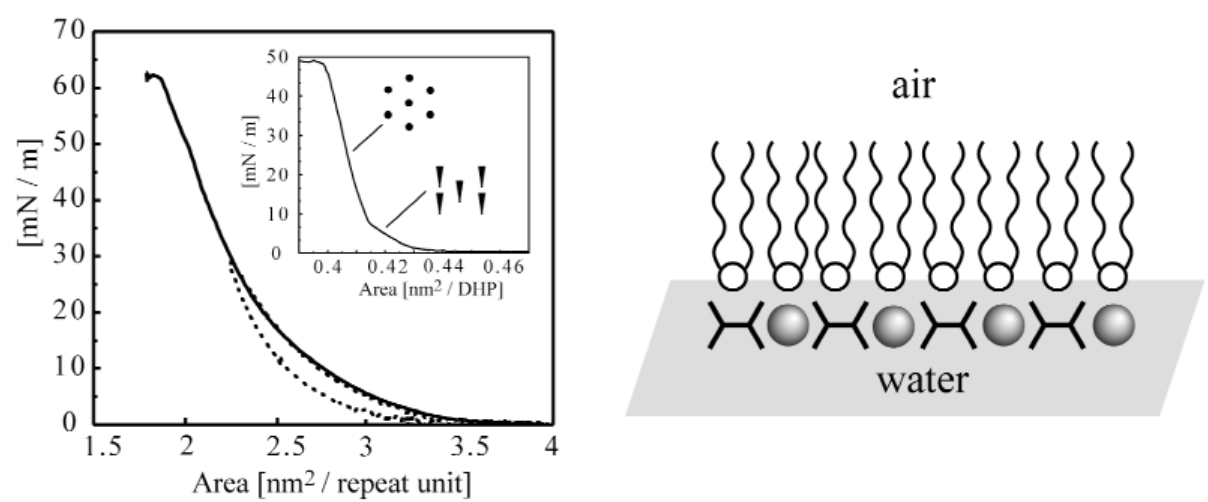

Fig. 1 Left: Compression isotherm (solid line) and expansion hysteresis (dotted line) of the PAC-1 monolayer at the air-water interface. The monolayer shows no distinct phase transitions. The area per molecule at the collapse pressure is $\sim 2.2 \mathrm{~nm}^{2}$ per molecule corresponding to six DHPs. The collapse pressure is remarkably high. The monolayer of neat DHP (inset) shows a distinct phase transition. The structure of the alkyl chains in both phases is schematically depicted. Right: Schematic bilayer architecture of the PAC-1 monolayer at the air-water interface. The amphiphilic component forms a (partially) charged template layer, to which MEPE adsorbs from underneath. (Adapted from ref. [53]).

indicating the high order of the LB layers. Notably, X-ray reflectance curves of a film made of $l$ layer shows only $l / 2$ Kiessig fringes before the first-order Bragg peak, indicating that the LB films are of $Y$ type and consist of amphiphile/MEPE sandwich layers. The LB layers are also oriented within the plane of the layers. Transfer of monolayers on the solid support causes macroscopic orientation of the MEPE rods along the transfer direction.

Thin layered films of MEPE can also be made by electrostatic layer-by-layer self-assembly (ELSA). Here, the positive charged MEPE is adsorbed on negatively charged interfaces, generally suitable polyelectrolytes. While this procedure offers many advantages, such as deposition from solution, simple equipment, coatings on arbitrary surfaces, etc., the resulting layers do not have the same degree of order as the LB films of PACs [55].

\section{Mesophases}

The molecular geometry of PAC with a rod-like backbone and flexible amphiphilic molecules suggests liquid-crystalline behavior [52,56]. The solid-state organization of a free-standing PAC-1 film is decoded by a combination of X-ray scattering and molecular modeling (Fig. 2). A first evaluation of the $\mathrm{X}$-ray scattering data indicates a lamella structure. Through molecular modeling, the initial structure is refined until a best match between calculated and experimental scattering curves is achieved. The hierarchical architecture of PAC-1 consists of flat lamellae of alternating interdigitated DHP and MEPE strata. This architecture is in marked contrast to that of corresponding LB multilayers. The LB films also have a lamellar superstructure but a lamella consists of four strata, namely, DHP, MEPE, MEPE, and DHP. In addition, the DHP molecules in LB films are not interdigitated due to the preorganization at the air-water interface. This comparison demonstrates how the modular nature permits controlling the architecture from molecular to macroscopic length scales through the boundary conditions during self-assembly. 

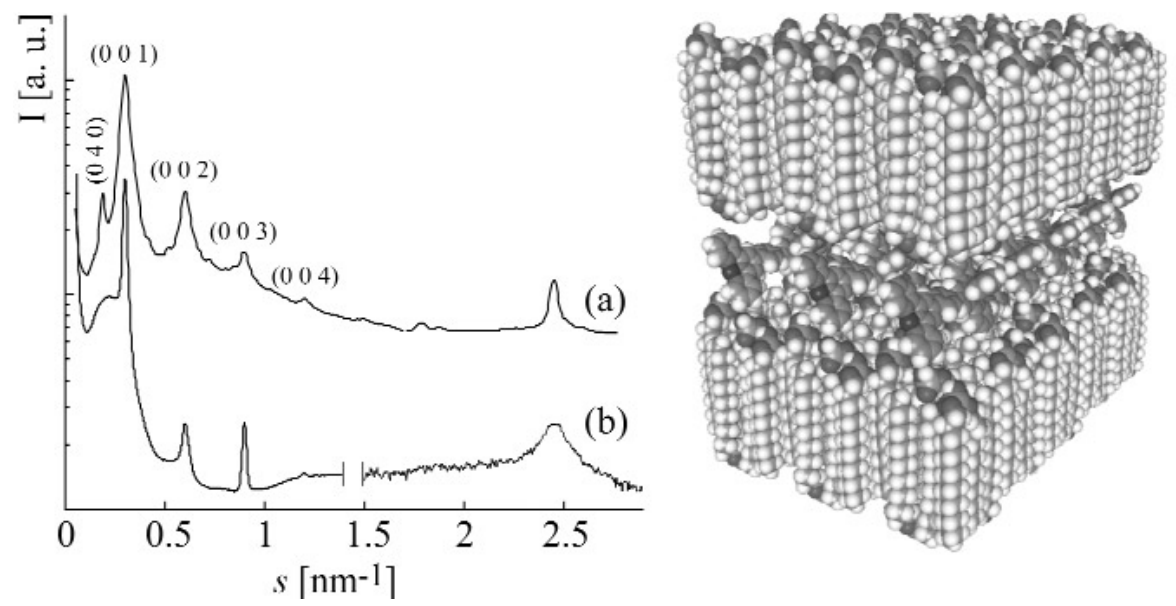

Fig. 2 Left: Calculated (a) and experimental (b) scattering curves of PAC-1. Right: Structural model on which the computed scattering pattern is based on showing the lamellar architecture of PAC with interdigitated amphiphiles. The hexagonal alkyl chain packing of the orthorhombic DHP unit cell comprises 12 molecules. This unit cell satisfies the steric requirements of the MEPE repeat unit. To preserve electroneutrality, four DHPs are deprotonated. Phosphate groups are randomly oriented toward the top or bottom of the stratum. (Adapted from ref. [56]).

\section{Nanostructures}

At interfaces, macromolecules often get kinetically trapped during adsorption due to their great size, which effectively prohibits reversible self-assembly processes and (long-range) ordering of macromolecules [57]. Even shape-persistent macromolecules like DNA or proteins exhibit generally only short-range ordering in surface-confined architectures [58]. On the other hand, numerous molecules self-assemble on suitable interfaces, such as long-chain alkanes on graphite, giving rise to highly ordered structures [59]. We, therefore, asked if it is possible to utilize molecular self-assembly to organize PACs at interfaces in predictable ways, where the amphiphilic component induces self-assembly on a suitable template layer.

Spin-coating a dilute solution of a mixture of PAC and a long-chain alkane at a mass ratio at around 1:10 on graphite leads to perfectly straight nanostructures of PAC-1 and PAC-2, with lengths of up to $200 \mathrm{~nm}$ as indicated by scanning force microscopy (SFM) (see Fig. 3) [51]. Notably, no crossing molecules or kinks are observed. The distance between the PAC rods is always $(5.5 \pm 0.3) \mathrm{nm}$, irrespective of the length of the alkane utilized, which indicates that the alkane layer orients and straightens the PAC, but does not determine the distances between adjacent PACs. This observation is explained by the following model: In the absence of alkanes, PACs are not oriented because the potential ripple of the graphite surface is too small. In contrast, coadsorption of PAC and alkanes results in perfectly straight PAC rods because the alkane molecules form a stable, highly ordered monolayer at the solid-liquid interface with a surface potential ripple larger enough to induce orientation of the rigid rod-type PACs 1 and 2. However, ordering is not strong enough to induce orientation of the flexible PAC-3. The modularity of this approach provides an entry to encode the value-adding physicochemical properties of metallosupramolecular devices into nanoscopic architectures that can be addressed and manipulated individually by scanning probe technique [60]. 

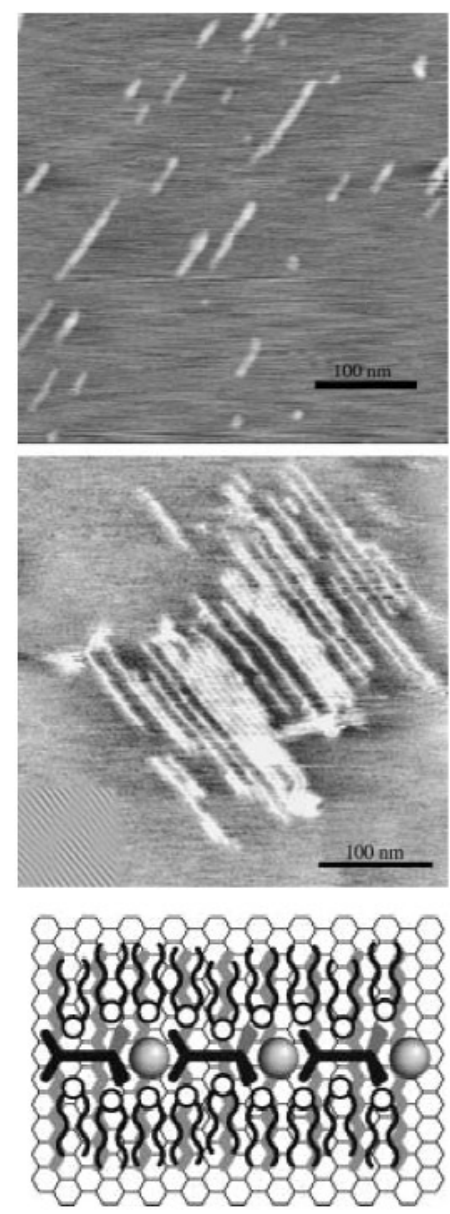

Fig. 3 Adsorption of PACs in predictable ways on the basal plane of graphite. Top: Representative SFM image of PAC- 1 adsorbed in the presence of $\mathrm{C}_{32} \mathrm{H}_{66}$ on the basal plane of graphite. Middle: SFM image of a sample prepared from about twice the concentration. The bottom layer consists of regular ordered lamellae of the self-assembled alkane monolayer (inset shows a filtered image of a part of the surface with the pure alkane monolayer). Perfectly straight PAC rods are observed on top of the alkane template layer. Bottom: The proposed model for the resulting nanostructures (simplified representation, not to scale). The alkanes (thick rods) adsorb epitaxially on the lattice of the basal plane of the underlying graphite surface. This alkane monolayer serves as a template for orienting the rigid rods of PAC-1 and PAC-2. (Adapted from ref. [51]).

Valkama et al. described a concept where a block copolymer, polystyrene-block-poly(4-vinylpyridine) (PS-block-P4VP), is complexed with dodecylbenesulfonate (DBS) as amphiphilic component and zinc dodecylbenesulfonate $\left[\mathrm{Zn}(\mathrm{DBS})_{2}\right]$, leading to polymeric supramolecular PS-blockP4VP[Zn(DBS) $]_{y}$ (Fig. 4) [61]. The mesoporous material achieved with this complex shows a lamellar structure, and even points toward a structural hierarchy for high-molecular-weight block copolymer. Moreover, $\mathrm{Zn}(\mathrm{DBS})_{2}$ can be extracted with a selective solvent such as methanol from the template, leading to a porous structure. Using poly(4-vinylpyridine) (P4VP), 2,6-bis(octylaminomethyl)pyridine and $\mathrm{Zn}(\mathrm{DBS})_{2}$, Valkama et al. further described a concept for self-organizing tri-component mixtures [63]. According to this concept, the $\mathrm{Zn}^{2+}$ centers coordinate to the pyridine groups of PVP and 2,6-bis(octylaminomethyl)pyridine. The amphiphilic counterions, DBS, bind to the positive metal center through electrostatic interactions and, therefore, also contribute to the resulting architecture. The 
a)

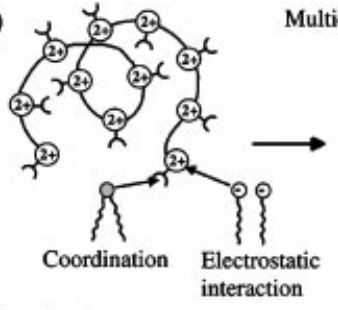

b)

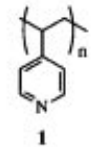

Multicomb polymeric supramolecule

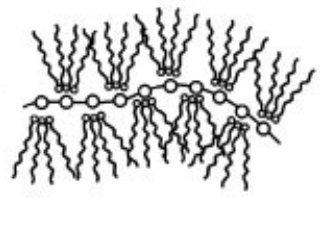

c)

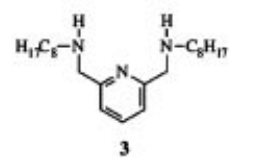

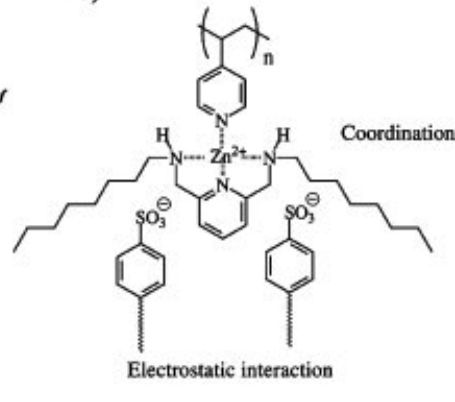

Fig. 4 (a) Multicomb polymeric superstructures derived from a polymeric backbone (1) and metal ion coordination of counter ions (2) and amphiphilic ligands (3). (b) Modules: P4VP (1), Zn(DBS) (2), and 2,6-bis(octylaminomethyl)pyridine (3). (c) Suggested complexation with a 1:1:1 molar mixture of 1,2, and 3 to form the polymeric metallosupramolecular poly[(4VP)Zn(2,6-bis(octylaminomethyl)pyridine)(DBS) $\left.{ }_{2}\right]$. (Adapted from ref. [63]).

structure is denoted as a multi-comb architecture with the format poly[(4VP)Zn(2,6-bis(octylaminomethyl)pyridine)(DBS $)_{2}$ ]. Because of the enhanced side-chain crowding, a cylindrical organization is obtained. Other hierarchical polyelectrolyte-amphiphile structures include molecular wires formed by halogen-bridged platinum complex $\left[\mathrm{Pt}(\mathrm{en})_{2}\right]\left[\mathrm{PtCl}_{2}(\mathrm{en})_{2}\right]^{4+}(\mathrm{en}=1$,2-diaminoethane $)$ with anionic amphiphiles, [62] and rigid metallo-host from a ruthenium-bipyridine complex and a glycolurilbased receptor cavity.

Drain [64] incorporated porphyrins into bilayer lipid membrane to study interfacial electrontransfer reactions, eventually leading to the formation of a molecular electronic device that functions as photogated transistor. The design principle of this molecular device is as follows: porphyrin molecules first self-assemble by either hydrogen bonding or metal ion coordination into linear arrays, and then the porphyrin arrays are self-organized into a lipid bilayer membrane. The length of the transmembrane assemblies is determined by the thermodynamics of porphyrin self-assembly and by the dimension and physical chemical properties of the bilayer. Thus, the porphyrin stacks adjust to the thickness of the bilayer. Electron acceptors and donors are placed in the separate compartments on either side of the membrane (Fig. 5, left). When illuminated with white light, a significant photocurrent is observed (Fig. 5, right). Only the assembled structures give rise to the photocurrent, as no current is observed from any of the component molecules. The fabrication of this photogated molecular electronic device from simple molecular components exploits several levels of self-assembly and self-organization. 


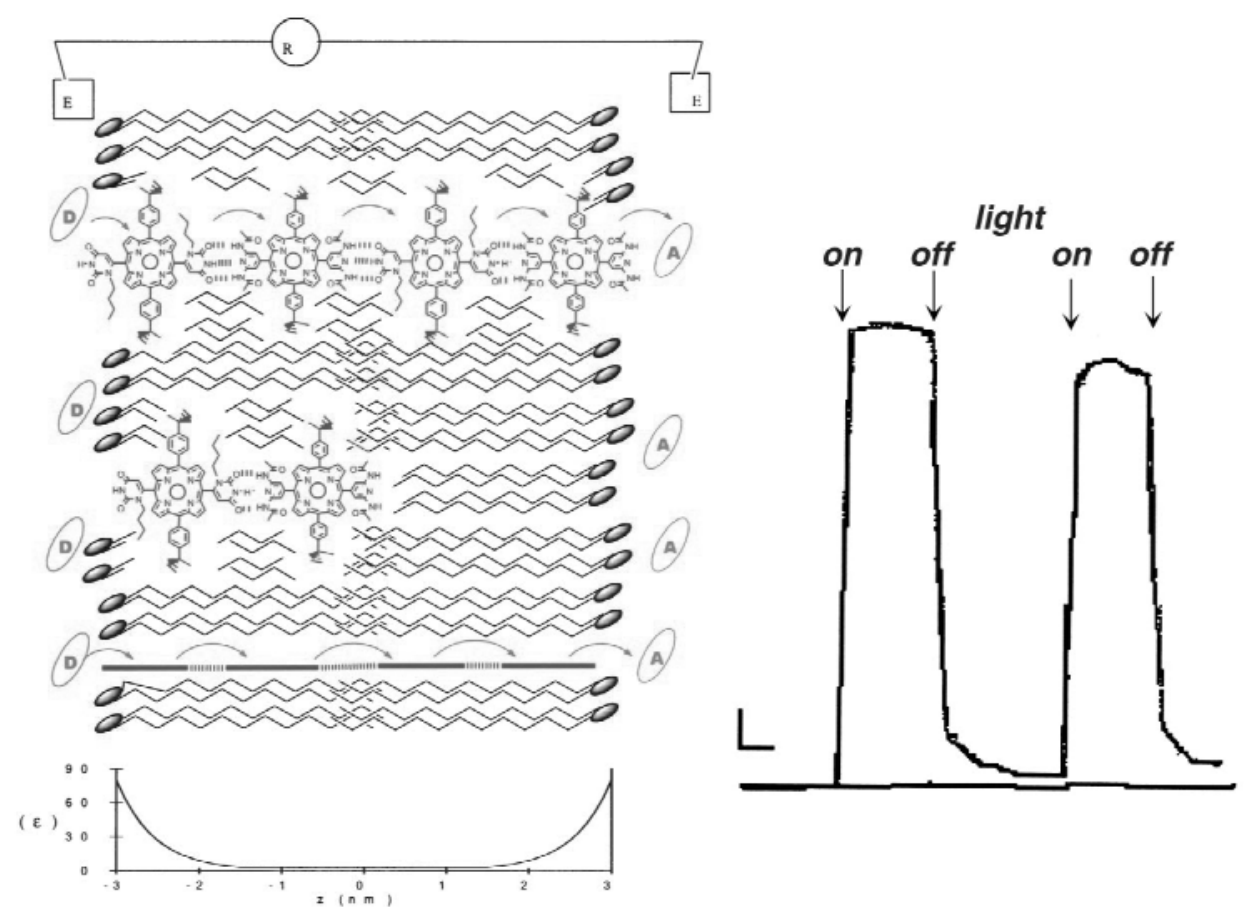

Fig. 5 Left: Schematic of the self-assembled porphyrin-membrane system acting as a photogated transistor. The porphyrin units self-assemble within the lipid bilayer. Porphyrin tapes spanning the entire membrane facilitate the flow of current through the device. The electron donor, $D$, is $\mathrm{K}_{4} \mathrm{Fe}(\mathrm{CN})_{6}$ and the acceptor, A, is anthraquinonesulfate (AQS). The bottom graph illustrates the dielectric constant across the membrane. Right: Strip chart recording of the resulting photocurrent. The horizontal scale bar represents $1 \mathrm{~min}$, and the vertical scale bar represents $6.9 \mathrm{nA}$. The bottom trace is the photocurrent of $\mathrm{Zn} \mathrm{5,} \mathrm{15-Urp} \mathrm{only.} \mathrm{(Adapted} \mathrm{from} \mathrm{ref.} \mathrm{[64]).}$

\section{Surfactant-encapsulated inorganic composites}

Self-assembly of surfactants and inorganic building blocks usually results in nanostructured organic-inorganic hybrid materials [65]. The involved inorganic building blocks include metal-oxide block, inorganic oligo-electrolyte species [66], lanthanide alkanoates [67], inorganic polyelectrolytes [68] and nanoparticles, and clusters, to name of few. These materials are analogous to the known organic polyelectrolyte-surfactant materials. Encapsulation of inorganic clusters with surfactant molecules not only changes the surface chemical properties such as the solubility, wetting, and adhesion, but also affects the processability of the inorganic materials used.

\section{Surfactant-encapsulated POM cluster}

The vast progress achieved in POM synthesis has so far not been complemented by a comparable development in POM surface chemistry. One possible strategy in surface modification is to exchange labile ligands, which are coordinatively bound to the peripheral metal atoms of the cluster core [69]. Due to the high stability of the terminal $\mathrm{M}-\mathrm{O}$ bond in polyoxomolybdates and -tungstates and the relatively slow ligand-exchange kinetics, especially for polyoxotungstates, chemical routes, which target on covalent modifications of the POM surface often lead to rearranged cluster cores. The prolonged reaction times and the rather vigorous reaction conditions often lead to mixtures of chemical derivatives of the original clusters in only moderate or low yields [70].

An alternative strategy described here relies on a ligand-exchange process in the second coordination sphere: the counter cations from the hydration sphere of the POM anions are replaced by suit- 


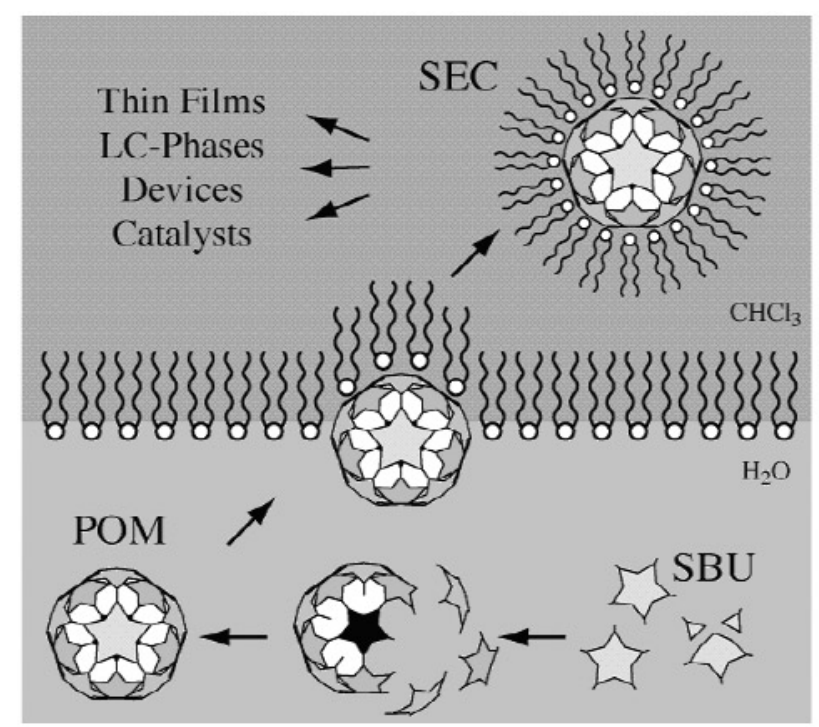

Fig. 6 Sequential self-assembly of POMs from SBU and concomitant amphiphilic self-assembly followed by phase transfer of SECs into the organic phase.

able amphiphiles, resulting in discrete SUMOs; due to the close packing of the long-chain amphiphiles on the surface of the POM we coined the term "surfactant-encapsulated clusters" (SECs) to emphasize the particular architecture of these core-shell-type assemblies (Fig. 6). This colloid chemical approach has been successfully used in the past to stabilize a variety of semiconductor and precious metal nanoparticles [71], but has not been pursued in POM chemistry with the purpose of producing discrete supramolecular assemblies [72].

Most SECs are prepared in a straightforward two-step procedure: first, a water-soluble salt of the POM is prepared and its structure is characterized by standard analytical methods (e.g., single-crystal $\mathrm{X}$-ray structure analysis). In the second step, an aqueous solution of the POM salt is treated with a water-immiscible organic solvent containing an appropriate amount of a cationic surfactant. This preparation scheme permits characterization of the materials brought into use at each step. Besides alkylammonium compounds, this approach has also been successfully used to encapsulate POMs with dendritically branching amphiphiles [73-76]. These results show that surfactant-encapsulation is widely applicable to different POM clusters and amphiphilic systems. These SECs form intriguing supramolecular architectures that can be compared to the structures of naturally occurring capsule-forming proteins such as the iron storage protein ferritin [77].

In contrast to our approach, Moriguchi et al. prepared a decatungstate-containing bilayer composite, DODA/[ $\left.\mathrm{W}_{10} \mathrm{O}_{32}\right]^{4-}[78]$, by using one-phase reaction: an aqueous solution of $\left[\mathrm{W}_{10} \mathrm{O}_{32}\right]^{4-}$ is added to a quaternary aqueous alkyammonium compound under vigorous stirring, which immediately results in precipitates. After filtration, washing, and drying in vacuum, the resulting complex of DODA/ $\left[\mathrm{W}_{10} \mathrm{O}_{32}\right]^{4-}$ does not dissolve in water, ethanol, and 2-propanol, but only chloroform. Chambers et al. reported another more sophisticated strategy to syntheses the first bis(alkyl) substituted amphiphilic, asymmetrical POM species $\left\{\left[\mathrm{CH}_{3}\left(\mathrm{CH}_{2}\right)_{3}\right]_{4} \mathrm{~N}\right\}_{4}\left\{\left[\mathrm{CH}_{3}\left(\mathrm{CH}_{2}\right)_{11} \mathrm{Si}\right]_{2} \mathrm{OSiW}_{11} \mathrm{O}_{39}\right\}$ by adding 2 equiv of dodecyltrichlorosilane in $\mathrm{CH}_{3} \mathrm{CN}$ to an aqueous solution of the Keggin lacunary POM precursor at $50{ }^{\circ} \mathrm{C}$ [79]. It also yields an LB monolayer at the air-water interface that is stable and forms reversibly as evident by the lack of hysteresis in compression-expansion cycles. 


\section{Structural characterization of SECS}

Analytical characterization of such large assemblies constitutes an enormous challenge in particular because single-crystal X-ray diffraction cannot be used due to the lack of long-range order of the liquid crystal-like SEC materials. A host of complementary techniques was used to probe the structural integrity of the POM in the SEC. The presence of the POM anion in the SEC is proven by Raman, infrared, and UV/vis spectroscopy due to characteristic vibrational and electronic transitions of the cluster anions. The surfactant shell can be investigated by ${ }^{1} \mathrm{H}$ NMR spectroscopy, which reveals that the positively charged head-groups of the surfactants point toward the negatively charged cluster surface. Both neutron and X-ray scattering can be used to examine the outer sphere and the particle core of the SEC and confirm that a single-cluster anion resides within the SEC. Analysis of the scattering data is in agreement with the dimensions of the POM anions as determined by single-crystal X-ray structure analysis. These measurements answer the important question whether or not the structural integrity of POM cluster is preserved in aqueous solution and in the SECs. In addition, molecular dynamics (MD) simulations are also a promising tool to refine dynamic structure models of SECs down to atomic resolution.

Experiments with different surfactant/POM combinations indicate that steric requirements for the packing of the surfactant alkyl chains and the molecular balance of the hydrophobic/hydrophilic properties play an important role in stabilizing the structure of the surfactant-encapsulated clusters. To give an example, aqueous solutions of the partially reduced POM $\left[\mathrm{H}_{3} \mathrm{Mo}_{57} \mathrm{~V}_{6}(\mathrm{NO})_{6} \mathrm{O}_{83}\left(\mathrm{H}_{2} \mathrm{O}\right)_{18}\right]^{21-}$, [Mo57], were equally treated with stoichiometric quantities of the commercially available surfactants dioctadecyldimethylammonium bromide [DODA $\cdot \mathrm{Br},\left(\mathrm{CH}_{3}\right)_{2}\left(\mathrm{C}_{18} \mathrm{H}_{37}\right)_{2} \mathrm{~N} \cdot \mathrm{Br}$ ], octadecyl trimethylammonium bromide $\left[\left(\mathrm{CH}_{3}\right)_{3}\left(\mathrm{C}_{18} \mathrm{H}_{37}\right) \mathrm{N} \cdot \mathrm{Br}\right]$, or trioctadecylmethylammonium bromide $\left[\mathrm{CH}_{3}\left(\mathrm{C}_{18} \mathrm{H}_{37}\right)_{3} \mathrm{~N} \cdot \mathrm{Br}\right]$; the transport of the Mo57 cluster into the organic phase was only achieved with the former DODA surfactant while phase transfer of the cluster failed or was incomplete in the case of the latter surfactants. From the organic solution, a compound corresponding to the empirical formula (DODA) ${ }_{20}\left(\mathrm{NH}_{4}\right)$ [Mo57] was isolated and its physicochemical properties have been studied with great detail in our groups [73]. Results from analytical ultracentrifugation, small-angle X-ray scattering, and Langmuir compression isotherms are consistent with a single Mo57 core encapsulated within a shell of 20 DODA molecules. One single ammonium cation was introduced into the molecular formula to compensate the 21 negative charges of the cluster anion. Although the applied methods do not allow to unambiguously detecting a single ammonium cation in such a large assembly, this is a reasonable postulate: The center of the cluster anion bears a cavity suitable for binding an ammonium cation. In fact, the cavity with its preorganized oxygen electron pairs resembles the binding site of ammonium-binding crown ethers. In contrast to the water-soluble starting material $\left(\mathrm{NH}_{4}\right)_{21}$ [Mo57], the SEC (DODA $)_{20}\left(\mathrm{NH}_{4}\right)$ [Mo57] dissolves readily in organic solvents such as benzene, toluene, or chloroform. The solubility properties suggest that the alkyl chains form a compact hydrophobic shell, which shields the enclosed cluster anion. To demonstrate the high stability of this compound, an aqueous dispersion of the SEC was refluxed and sonicated for several minutes, upon which no signs of decomposition occurred.

Another SEC with an intricate supramolecular architecture, which appears promising in terms of host-guest chemistry and homogeneous size-selective catalysis, is DODA 40 $\left.\subset \mathrm{Mo}_{132} \mathrm{O}_{372}\left(\mathrm{CH}_{3} \mathrm{COO}\right)_{30}\left(\mathrm{H}_{2} \mathrm{O}\right)_{72}\right]\left(\mathrm{DODA}_{40}\left(\mathrm{NH}_{4}\right)_{2}\right.$ [Mo132]) (Fig. 7) [74,75]. Based on elemental analysis, 40 DODA molecules encapsulate the cluster, leading to a discrete, nearly spherical particle with a molecular mass of approximately $43.900 \mathrm{~g} / \mathrm{mol}$. The solvent-accessible surface (SAS) of the Mo132 cluster calculated for a probe radius of $0.28 \mathrm{~nm}$ is approximately $33.4 \mathrm{~nm}^{2}$, which yields an average surfactant area of $0.84 \mathrm{~nm}^{2}$. Within the given range of uncertainty, this corresponds reasonably well to the empirical value of $32( \pm 8) \mathrm{nm}^{2}$ for the complete surface area of 40 DODA molecules [80].

Geometric matching of the two juxtaposed ionic surfaces constituted by the POM anion and the surfactants may be of critical importance for driving the self-encapsulation process to completion. The surface charge density of Mo132 is such that all DODA molecules find sufficient space to form a sin-

(C) 2004 IUPAC, Pure and Applied Chemistry 76, 1847-1867 


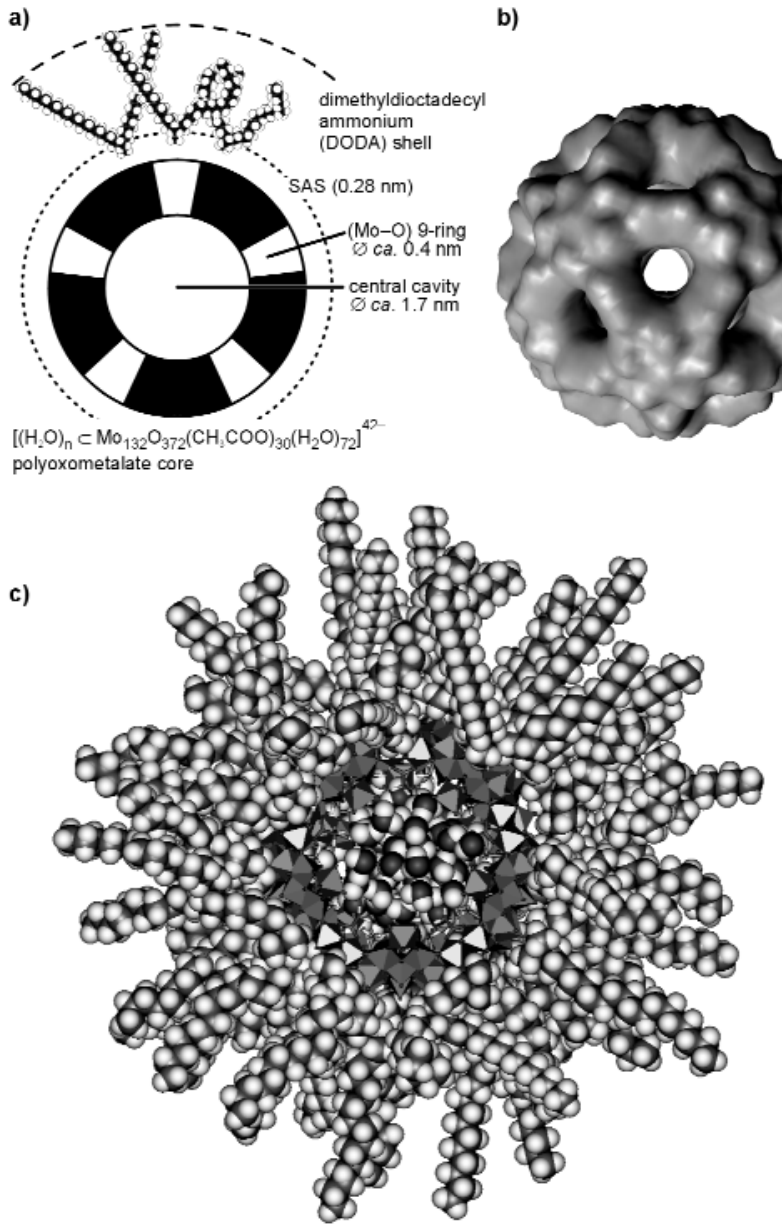

Fig. 7 Supramolecular architecture of (DODA) ${ }_{40}\left(\mathrm{NH}_{4}\right)_{2}$ [Mo132]. (a) Schematic representation of the core-shell structure of a single SEC. (b) Solid rendered representation of the Connolly surface of the Keplerate cluster Mo132. (c) Cross-section through an SEC model showing the surfactant shell and the clathrated $\mathrm{H}_{2} \mathrm{O}$ molecules in spacefilling representations, while the Mo-O framework is displayed as polyhedral model. (Adapted from refs. [74,75]).

gle layer at a van der Waals distance to the cluster surface. The covered surface area of an $0.84 \mathrm{~nm}^{2} /$ DODA molecule furthermore suggests a rather tight packing of the amphiphile at the cluster surface. The SAS of Mo132 for a 0.28 -nm probe displays a continuous spherically shaped surface, which indicates that the DODA cations cannot penetrate the large central cavity of the Keplerate. In contrast, the SAS of Mo132 for a 0.14-nm probe, which is often referred to as the water-accessible (Connolly) surface, extends into the central cavity through each of the 20 noncircular (Mo-O) 9-ring openings (Fig. 7B). The whole assembly of cluster and surfactant on this level of structural organization resembles a reversed micelle in which the hydrophilic cavity is completely filled by the large cluster anion. An MD simulation of the SEC gives an idea of the packing of the surfactant molecules around the nanosized cluster. The simulation in Fig. 7C indicates that the cluster is completely encapsulated and shielded by the long hydrophobic octadecyl chains, which explains the good solubility of the SECs in nonpolar organic solvents.

Other surfactant-encapsulated POM complexes include (DODA) ${ }_{16} \mathrm{As}_{4} \mathrm{~W}_{30} \mathrm{Cu}_{4} \mathrm{O}_{112} \cdot 114 \mathrm{H}_{2} \mathrm{O}$, $[81,82] \mathrm{C} 16 \mathrm{TA} /\left[\mathrm{EuW}_{10} \mathrm{O}_{36}\right]^{9-}(\mathrm{C} 16 \mathrm{TA}=$ hexadecyl trimethylammonium cation $)$ [83] obtained by employing a similar method and the complexes of the "giant Ferris wheel" $\left[\left(\mathrm{MoO}_{3}\right)_{176}\left(\mathrm{H}_{2} \mathrm{O}\right)_{80} \mathrm{H}_{32}\right]^{32-}$ 
with a variety of surfactants [84]. The SEC, (DODA) ${ }_{16} \mathrm{As}_{4} \mathrm{~W}_{30} \mathrm{Cu}_{4} \mathrm{O}_{112} \cdot 114 \mathrm{H}_{2} \mathrm{O}$, can form a stable monolayer at the air-water interface. However, the ellipsoid is significantly distorted at the air-water interface, although it is believed that the general core-shell structure seems to remain. The complexation of wheel-shaped cluster with surfactants delivers supramolecular organic-inorganic hybrid aggregates of extended disk-like shape, consisting of a rigid and hydrophiphilic core and a flexible hydrophobic shell. Therefore, SECs can be similar to organic liquid crystals, and undergo self-assembly into columnar liquid-crystalline structure [84].

The latest development in this field is the design of artificial enzymes, so-called dendrizymes, which mimic the structure and function of naturally occurring catalytically active metalloproteinsdendron-encapsulated clusters, such as $\left(\mathrm{C}_{52} \mathrm{H}_{60} \mathrm{NO}_{12}\right)_{12}\left[\mathrm{Mn}\left(\mathrm{H}_{2} \mathrm{O}\right)_{3}\left(\mathrm{SbW}_{9} \mathrm{O}_{33}\right)_{2}\right]$ [76]. Here, the catalytic activity of POMs is combined with the steric properties of tailored dendritic surfactants toward size-selective catalytic systems. The SEC thereby bears a certain resemblance to natural metalloproteins ("dendrizymes"). Elemental analysis indicates that the POM anion is encapsulated in a densely packed shell of 12 dendrons, thus, yielding a discrete, hydrophobic supramolecular architecture with a molar mass of $15778 \mathrm{~g} / \mathrm{mol}$.

The reasons for spontaneously occurring SEC assembly are not well understood yet, since the accurate values of the contributing enthalpy and entropy terms are difficult to determine. Currently, we assume that the process is mainly driven by an increase in Coulomb interactions: placing the cationic head-groups in close vicinity to the POM surface efficiently screens the electrostatic charge of the encapsulated anion. Hydrophobic interactions between the alkyl-chains of the close-packed surfactant shell may furthermore stabilize the SEC. Finally, the gain of hydration enthalpy upon release of counter anions (e.g., $\mathrm{Cl}^{-}$or $\mathrm{Br}^{-}$) into the aqueous phase, and the entropically favorable liberation of a huge number of ammonium cations and water molecules from the cluster surface may equally contribute to the free energy of SEC formation.

\section{Langmuir-Blodgett films of SECs}

Compared with "naked" POM clusters, SECs have the following feature: the surfactant shell improves the stability of the encapsulated cluster against fragmentation, enhances the solubility of the encapsulated cluster in nonpolar, aprotic organic solvents, neutralizes the charge of anionic POM, therefore leading to discrete, electrostatically neutral assemblies, and alters the surface chemical properties of the POM (e.g., self-aggregation, surface adhesion, wetting behavior) in a predictable manner. Of these features, the hydrophobic nature of SECs is especially interesting because it permits us to produce welldefined thin films by the LB technique.

The SECs can be directly spread at the air-water interface to yield a homogeneous SEC monolayer. From Langmuir isotherms, the surface area of a single (DODA) ${ }_{20}\left(\mathrm{NH}_{4}\right)$ [Mo57] is determined to be $10.4 \mathrm{~nm}^{2}$, which corresponds to an object with a diameter of $3.6 \mathrm{~nm}$ (Fig. 8). The DODA $_{40}\left(\mathrm{NH}_{4}\right)_{2}[\mathbf{M o 1 3 2}]$ occupies an area of $15 \mathrm{~nm}^{2}$, which corresponds to a diameter of $4.4 \mathrm{~nm}$. Both values are in excellent agreement with the proposed structural model in which a single cluster anion resides within a close shell of surfactant molecules. Analytical characterization of SEC Langmuir films by Brewster-angle microscopy, optical ellipsometry, and grazing-angle X-ray diffraction confirm monolayer coverage [85].

LB transfer of SEC monolayers is achieved by the following procedure: SECs are spread from chloroform solution on the water surface, the resulting SEC monolayer is compressed and the film is transferred at constant surface pressure onto the solid substrate. The deposited substrates include silicon, quartz, and gold-sputtered glass slides. The substrate is immersed in the subphase before spreading and multilayers are formed by repeated LB transfer. The transfer ratio is close to unity in all cases. Investigation with optical ellipsometry and UV/vis-spectroscopy demonstrate that LB transfer is very reproducible and that film growth is essentially linear, that is, in each dipping cycle equivalent amounts of SECs are transferred on the substrate. X-ray reflectivity (XRR) of SEC LB multilayers on silicon substrates shows well-resolved Kiessig fringes, indicating a uniform film thickness. In addition, several

(C) 2004 IUPAC, Pure and Applied Chemistry 76, 1847-1867 


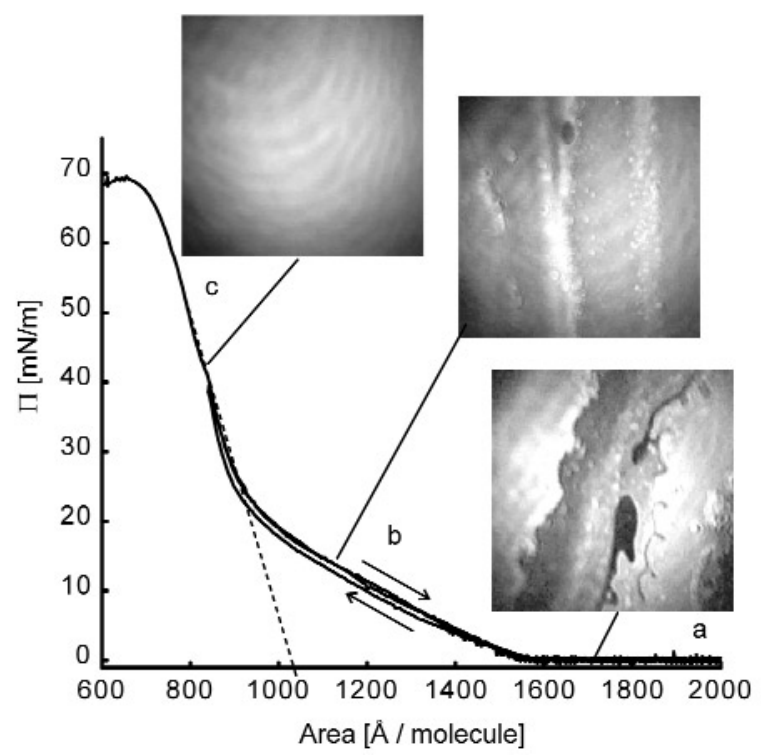

Fig. 8 Representative surface-pressure $\left(\pi\right.$-A) diagram of a (DODA) ${ }_{20}\left(\mathrm{NH}_{4}\right)[\mathbf{M o 5 7}]$ monolayer at the air-water interface. The inserted photographs stem from Brewster angle microscopic images at different surface pressures. (a) $\pi=0 \mathrm{mN}$; (b) $\pi=20 \mathrm{mN}$; (c) $y=40 \mathrm{mN}$. (Figure reproduced from ref. [73], with permission).

Bragg reflections are discernible, which implies that these LB films have an internal layered structure contrasting the structure of corresponding ELSA multilayers.

The static contact angle, $\gamma$, of (DODA) ${ }_{20}\left(\mathrm{NH}_{4}\right)$ [Mo57] LB multilayers is $102^{\circ}$ for water and $31^{\circ}$ for hexadecane. Similarly, the water contact angle of $\mathrm{DODA}_{40}\left(\mathrm{NH}_{4}\right)_{2}[$ Mo132] LB multilayers amounts to $97^{\circ}$. These values clearly indicate the hydrophobic nature of the SEC-coated substrate surface and demonstrate how efficiently the DODA surfactant shell screens the underlying hydrophilic cluster. The absolute values of the contact angles suggest that the SEC alkyl chains are somewhat disordered. For comparison, a methyl-terminated surface of a self-assembled monolayer typically has contact angle in the range of $110-115^{\circ}[86]$.

It is not yet clear how SECs are stabilized at the air-water interface because hydrophobic compounds typically aggregate and float as lenses on the water surface. Since SECs have finite water contact angles, partial wetting may cause a partial immersion of the spherical SEC into the aqueous subphase [87]. This could trap the SEC at the air-water interface and would prevent aggregation to droplets.

In addition, we found that SECs spontaneously assemble into highly ordered two-dimensional arrays. TEM studies on SEC thin films deposited on solid substrates either by LB transfer or, alternatively, by simple evaporation of diluted SEC solutions, reveal that SECs have a strong tendency to self-assemble into extended, well-ordered two-dimensional arrays. Figure 9a, as an example, shows a TEM micrograph of a thin film of DODA 40 ( $\left.\mathrm{NH}_{4}\right)_{2}[\mathbf{M o 1 3 2}]$. The inorganic cores of the SECs appear as dark spots embedded in a bright matrix of surfactant molecules. Monolayer regions, regions consisting of a bilayer (darker) and the uncovered substrate (brighter) are clearly distinguishable. Small domains exhibit hexagonal arrays of SECs corresponding to a 2-dimensional close packing of spherical particles (arrows). Both the diameter of the dark objects (approx. $3 \mathrm{~nm}$ ) as well as the average distance between them (approx. $4.5 \mathrm{~nm}$ ) are consistent with the proposed SEC model. In thicker films, the order improves and becomes 3-dimensional. An ordered region is shown in Fig. 9b; the related electron diffraction pattern (insert) clearly reveals long-range order (spots rather than rings) and a threefold symmetry of the pattern of reflections corresponding to a spacing of $4.2 \mathrm{~nm}$. The packing of the SECs may be tentatively 

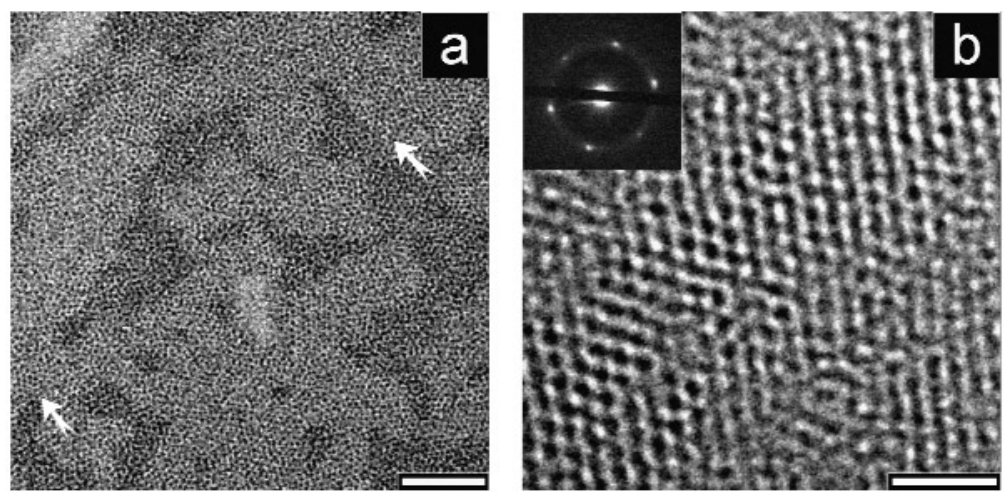

Fig. 9 (a) TEM micrograph of a thin film of DODA $40\left(\mathrm{NH}_{4}\right)_{2}$ [Mo132] (scale bar $50 \mathrm{~nm}$ ). Extended monolayers, interspersed with holes and double-layer regions are visible. Arrows mark some regions of apparent hexagonal order. (b) TEM micrograph of an ordered region of a thicker film at high magnification (scale bar $20 \mathrm{~nm}$ ). The insert shows a low-angle electron diffraction pattern recorded from a larger area $\left(5 \mu \mathrm{m}^{2}\right)$ containing the region shown. (Micrographs reproduced from [75]).

described by an fcc lattice with a cubic unit cell axis of approximately $6 \mathrm{~nm}$. The observed diffraction pattern then corresponds to the close packing of SECs in a (111) plane at normal orientation to the electron beam. It is noteworthy that upon heating thick SEC films, dewetting and terracing is observed, as in the case of block copolymers.

\section{FUNCTIONS OF SECs}

\section{Liquid-crystalline phases}

In a few cases it has been shown that SECs exhibit liquid-crystalline behavior $[78,84,88]$. In these cases, the liquid crystallinity is provided by the surfactant component, whereas the inorganic component effectively follows the direction of the surfactant phase.

\section{Photocatalysis}

The highly ordered and assembled surfactant shells of SECs control the amount and the spatial arrangement of POM ions. Therefore, the hydrophilic interlayers of SECs are expected to be a spatially and chemically constrained reaction field for size- and shape-controlled synthesis of inorganic nanoparticles and catalytic reaction. Moriguchi et al. used DODA/[ $\left.\mathrm{W}_{10} \mathrm{O}_{32}\right]^{4-}$ composite as the photocatalyst for the conversion of 2-propanol to acetone. The DODA/[ $\left[\mathrm{W}_{10} \mathrm{O}_{32}\right]^{4-}$ composite powder dispersed in 2propanol photocatalyzes the oxidative dehydrogenation of 2-propanol into acetone in the presence of oxygen and under UV irradiation. The DODA/ $\left[\mathrm{W}_{10} \mathrm{O}_{32}\right]^{4-}$ exhibited a unique temperature dependence; the photocatalytic activity is drastically enhanced above the phase-transition temperature of the amphiphilic bilayer. When the DODA/[ $\left.\mathrm{W}_{10} \mathrm{O}_{32}\right]^{4-}$ composite was combined with Pt nanoparticles, the photocatalytic dehydrogenation of 2-propanol into acetone and $\mathrm{H}_{2}$ proceeded in the absence of oxygen because $\mathrm{Pt}$ promotes the reoxidation of protonated $\left[\mathrm{H}_{2} \mathrm{~W}_{10} \mathrm{O}_{32}\right]^{4-}$ to the original $\left[\mathrm{W}_{10} \mathrm{O}_{32}\right]^{4-}$ (Fig. 10).

Moreover, SECs are promising candidates for diverse applications, including electrocatalytic display devices and photonic materials [83]. The results observed until now are still quite limited. Further studies are necessary to elucidate the full potential of these materials.

\section{Surfactant-encapsulated semiconductor nanoparticles}

The synthesis, purification, and isolation of stable, discrete nanoparticles preferentially with a narrow size distribution and tailored surface chemical properties represents a considerable challenge because 

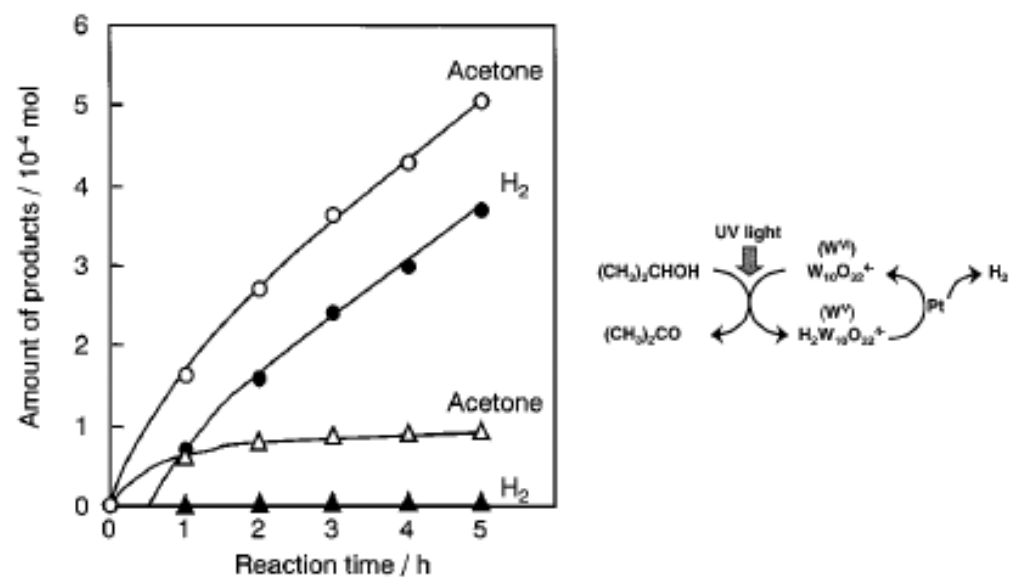

Fig. 10 Left: Time course of photocatalytic reaction of DODA/[ $\left.\mathrm{W}_{10} \mathrm{O}_{32}\right]^{4-} / \mathrm{Pt}[0.3]$ (circle) and DODA/[ $\left.\mathrm{W}_{10} \mathrm{O}_{32}\right]^{4-}$ (triangle) for the oxidation dehydrogenation of 2-propanol under nitrogen gas atmosphere at $35{ }^{\circ} \mathrm{C}$. The catalysts $\left(1 \times 10^{-4} \mathrm{~mol}\right)$ are dispersed in $200 \mathrm{ml}$ of 2-propanol. Right: Catalytic cycle of the dehydrogenation of 2-propanol to acetone with DODA/[ $\left.\mathrm{W}_{10} \mathrm{O}_{32}\right]^{4-} / \mathrm{Pt}[x]$.

the large surface energy promotes aggregation to minimize the surface area. A successful synthesis should, therefore, result in monodisperse nanoparticles with robust surface passivation. Passivation or capsulation is one of the most useful ways to achieve this goal. Especially, considerable interests have focused on organic-inorganic hybrid composites, in which semiconductor nanocrystallites are encapsulated in the organic phase [89-98].

The strategy for the encapsulation of POM cluster with surfactants is also suitable for the synthesis and isolation of stable, monodisperse surfactant-encapsulated semiconductor clusters. This selfassembly strategy relies on an ion exchange process of the cluster counterions with surfactants. The semiconductor nanoparticles are first synthesized according to the established experimental procedure. Then, self-assembly of charged semiconductor clusters and dialkylammonium surfactants results in encapsulation and formation of discrete, encapsulated semiconductor nanoparticles. This approach has been applied to a variety of particles [99], including gold colloids [100], metal [101], and metal oxide clusters [102]. The advantage of this approach is that the encapsulation of nanoparticles with surfactants results in hydrophoblic SECs, which are readily isolated as solid powder. Moreover, these semiconductor-SECs possess many interesting properties and are, therefore, of considerable technological interest [103]. Encapsulation effectively tailors the surface chemical properties of semiconductor nanoparticles, including solubility and surface activity. For example, the CdTe-SECs readily dissolve in common organic solvents, implying that the surfactant molecules formed a closed, hydrophobic shell around semiconductor nanoparticles with the positive head-groups of the surfactant molecules binding to the surface carboxylates [104]. We note that the encapsulated CdTe particles have a superior photochemical stability compared to the native clusters (Fig. 11). The surfactant shell may decrease the interfacial chemical reactivity, thus rendering the assembly more stable.

Mériguet et al. also used this direct liquid-liquid phase-transfer method to transfer maghemite nanoparticles, $\gamma-\mathrm{Fe}_{2} \mathrm{O}_{3}$, with didocyldimethylammonium bromide (DDAB) from a water-based ferrofluid into a cyclohexane-based ferrofluid [105]. The adsorbed surfactant can be controlled and reaches a saturation value once the nanoparticle surface is fully covered. The encapsulated $\gamma-\mathrm{Fe}_{2} \mathrm{O}_{3}$ nanoparticles are very stable, and the aggregation does not appear even upon aging. 


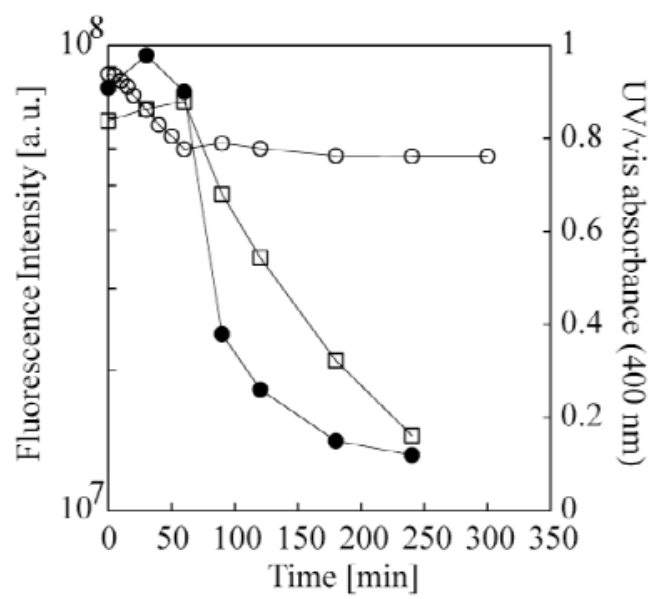

Fig. 11 Fluorescence intensity of CdTe clusters (open squares) and CdTe-SEC (open circles) as a function of time. The CdTe-SEC showed nearly constant fluorescence intensity under irradiation at the excitation wavelength $(400 \mathrm{~nm})$. By contrast, the fluorescence intensity of parent CdTe clusters decays under identical conditions. Also shown is the UV-vis absorbance at $400 \mathrm{~nm}$ of the CdTe clusters (full circles). The diminution with time corresponds to a loss of material within the probe beam volume (precipitation), which causes the decrease of fluorescence intensity. (Adapted from ref. [104]).

\section{CONCLUSIONS AND OUTLOOK}

In this short review, we showed that surfactant encapsulation is a versatile, highly economic procedure to alter the surface chemical properties of various building blocks from metallosupramolecules (PACs) to inorganic nanocrystals (SECs). The PACs and SECs are organized through electrostatic binding and/or hydrophobic interaction. These building blocks are nested within a shell of surfactants, thus leading to discrete, electrostatically neutral, hydrophobic molecular wires or core-shell particles. An alternative strategy is based on the exchange of the counter cation or counter anion of the building blocks with oppositely charged macromolecules, leading to hybrid nanostructured materials [106].

A central challenge is to characterize these complex soft materials lacking crystalline order, establish quantitative structure-property relationship at a sufficiently accurate level, and control effectively the structure and functionality.

Although rapidly increasing materials are reported in the last years, the methods to incorporate these nanoscaled self-assembled materials or objects into devices on a production (economically feasible) scale have significantly lagged behind. It has been recognized that these self-assembled systems will have to subsequently, or concomitantly, self-organize into hierarchical structures that may also form interconnects to the macroscopic world. Therefore, for many of these devices based on organic or hybrid inorganic-organic compounds, in analogy to biological systems, the structural organization of supramolecular assemblies need to be controlled. Moreover, the potential usefulness and functionality of these materials and systems have largely rested on proof of principle experiments, such as those using scanning-probe tips to construct and evaluate the device. The future developments in the preparation and functionalization of suitable surfactant-encapsulated complexes, the advancements in controlled structural organization, and the progress in new tools to construct the device will surely further promote this development.

\section{ACKNOWLEDGMENTS}

Helmuth Möhwald is acknowledged for valuable discussions. SL is grateful to the AvH foundation for a research fellowship, and DGK and DV thank BMBF, DFG, and VW foundation for financial support. 


\section{REFERENCES}

1. P. Ball. Nature 409, 413 (2001).

2. (a) A. P. Alivisatos, P. F. Barbara, A. W. Castleman, J. Chang, D. A. Dixon, M. L. Klein, G. L. McLondon, J. S. Miller, M. A. Ratner, P. J. Rossky, S. T. Stupp, M. F. Thompson. Adv. Mater. 10, 1297 (1998); (b) M. A. Fox. Acc. Chem. Res. 32, 201 (1999); Ann. N. Y. Acad. Sci., A. Aviram and M. Ratner (Eds.), 852, 1 (1998); (c) M. A. Reed. MRS Bull. 26, 113 (2001).

3. (a) C. M. Drain and D. Mauzerall. Bioelectrochem. Bioenerg. 24, 263 (1990); (b) C. D. Drain, B. Christensen, D. Mauzerall. Proc. Natl. Acad. Sci. USA 86, 6959 (1989); (c) J.-M. Lehn. Angew. Chem. 102, 1347 (1990); Angew. Chem., Int. Ed. Engl. 29, 1304 (1990); (d) J. S. Lindsey. New J. Chem. 15, 153 (1991); (e) P. J. Stang and B. Olenyuk. Acc. Chem. Res. 30, 502 (1997); (e) Struct. Bonding, M. Fujita (Ed.), 96, 149 (2000).

4. J. D. Swalen, D. L. Allara, J. D. Andrade, E. A. Chandross, S. Garoff, J. Israelachvili, T. J. McCarthy, R. Murray, R. F. Pease, J. F. Rabolt, K. J. Wynne, H. Yu. Langmuir 3, 932-950 (1987).

5. M. Shimomura and T. Sawadaishi. Curr. Opin. Colloid Interface Sci. 6, 11 (2001).

6. (a) S. Kosmella, J. Kotz, K. Shirahama, J. Liu. J. Phys. Chem. B. 102, 6459 (1998); (b) Y. Okahata, G. Enna, K. Taguchi, T. Seki. J. Am. Chem. Soc. 107, 5300 (1985); (c) K. Taguchi, S. Yano, K. Hiratani, N. Minora, Y. Okahata. Macromolecules 21, 336 (1988).

7. D. A. Tomalia, Z. G. Wang, M. Tirrell. Curr. Opin. Colloid Interface Sci. 4, 3 (1999).

8. S. R. Quake and A. Scherer. Science 290, 1536 (2000).

9. M. D. Brown, A. G. Schaetzlein, I. F. Uchegbu. Int. J. Pharm. 229, 1 (2001).

10. B. H. Wolf, B. K. Keitemeier, A. E. Schmidt, G. H. Richter, G. Duncan. J. Prosthetic Dentistry 85, 401 (2001).

11. C. D. Wilkinson, M. Riehle, M. Wood, J. Gallagher, A. S. G. Cutis. Mater. Sci. Eng., C: Biomim. Supramol. Syt. 19, 263 (2002).

12. H. Otsuka, Y. Nagasaki, K. Kataoka. Curr. Opin. Colloid Interface Sci. 6, 3 (2001).

13. G. A. Mines, B.-C. Tzeng, K. J. Stevenson, J. Li, J. T. Hupp. Angew. Chem. 114, 162 (2002); Angew. Chem., Int. Ed. 41, 154 (2002).

14. Two reviews focused on polyelectrolyte-surfactant complex: (a) A. F. Thünemann. Prog. Polym. Sci. 27, 1473 (2002); (b) C. F. J. Faul and M. Antonietti. Adv. Mater. 15, 673 (2003).

15. M. Antonietti and J. Conrad. Angew. Chem., Int. Ed. Engl. 33, 1869 (1994).

16. M. Antonietti, J. Conrad, A. F. Thünemann. Macromolecules 27, 6007 (1994).

17. M. Antonietti, C. Burger, J. Effing. Adv. Mater. 7, 751 (1995).

18. F. Yeh, E. L. Sokolov, T. Walter, B. Chu. Langmuir 14, 4350 (1998).

19. S. Zhou, C. Burger, F. Yeh, B. Chu. Macromolecules 21, 8157 (1998).

20. S. Zhou, F. Yeh, C. Burger, B. Chu. J. Phys. Chem. B 103, 2107 (1999).

21. M. Antonietti, S. Henke, A. F. Thünemann. Adv. Mater. 8, 41 (1996).

22. M. Antonietti, M. Nesse, G. Blum, F. Kremer. Langmuir 12, 4436 (1996).

23. M. Antonietti, M. Maskos, F. Kremer, G. Blum. Acta Polym. 47, 460 (1996).

24. M. Tiitu, P. Hiekkataipale, J. Hartikainen, T. Mäkelae, O. Ikkala. Macromolecules 35, 5212 (2002).

25. J. Hartikainen, M. Lahtinen, M. Torkkeli, R. Serimaa, J. Valkonen, K. Rissanen, O. Ikkala. Macromolecules 34, 7789 (2001).

26. H. Kosonen, J. Ruokolainen, M. Knaapila, M. Torkkeli, K. Jokela, R. Serimaa, G. TenBrinke, W. Bras, A. P. Monkman, O. Ikkala. Macromolecules 33, 8671 (2000).

27. H. Kosonen, J. Ruokolainen, M. Knaapila, M. Torkkeli, R. Serimaa, W. Bras, A. P. Monkman, G. ten Brinke, O. Ikkala. Synth. Met. 121, 1277 (2001).

28. R. Maeki-ontto, K. de Moel, E. Polushkin, G. Alberda van Ekenstein, G. ten Brinke, O. Ikkala. Adv. Mater. 14, 357 (2002). 
29. (a) M. Antonietti, A. Kaul, A. F. Thünemann. Langmuir 11, 2633 (1995); (b) M. Antonietti, A. Wenzel, A. F. Thünemann. Langmuir 12, 2111 (1996).

30. (a) A. F. Thünemann, J. Beyermann, C. von Ferber, H. Löwen. Langmuir 16, 850 (2000); (b) V. P. Torchilin. J. Controlled Release 73, 137 (2001).

31. (a) J. G. Linhardt and D. A. Tirrel. Langmuir 16, 122 (2000); (b) S. General and A. F. Thünemann. Int. Pharm. J. 230, 11 (2001); (c) S. General, J. Rudloff, A. F. Thünemann. Chem. Commun. 534 (2002); (d) M. Dreja and W. Lennartz. Macromolecules 32, 3528 (1999).

32. (a) M. Dreja and W. Lennartz. Macromolecules 32, 3528 (1999); (b) C. F. L. Faul, M. Antonietti, R. D. Sanderson, H.-P. Hentze. Langmuir 17, 2031 (2001).

33. C. K. Ober and G. Wegner. Adv. Mater. 9, 17 (1997).

34. U. S. Schubert and C. Eschbaumer. Angew. Chem., Int. Ed. 41, 2892 (2002).

35. E. C. Constable. In Electronic Materials: The Oligomer Approach, VCH-Wiley, Weinheim (1998).

36. V. Bazai and F. Seandola. Supramolecular Photochemistry, Harwood, New York (1991).

37. J.-M. Lehn. In Supramolecular Chemistry: Concepts and Perspectives, pp. 139-195, VCH, New York (1995).

38. N. J. Long. Angew. Chem., Int. Ed. 34, 21 (1995).

39. V. Balzani and F. Scandola. Supramolecular Photochemistry, Ellis Horwood, New York (1991).

40. S. Decurtins, P. Gütlich, C. P. Kohler, H. Spiering, A. Hauser. Chem. Phys. Lett. 105, 1 (1984).

41. S. Decurtins, P. Gütlich, K. M. Hasselbach, A. Hauser, H. Spiering. Inorg. Chem. 24, 2174 (1985).

42. F. Renz, H. Oshio, H. Ksenofontov, M. Waldek, M. Spiering, P. Gütlich. Angew. Chem., Int. Ed. 39, 3699 (2000).

43. (a) I. V. Kozhevnikov. Chem. Rev. 98, 171 (1998); (b) N. Mizuno and M. Misono. Chem. Rev. 98, 199 (1998).

44. (a) I. A. Weinstock. Chem. Rev. 98, 113 (1998); M. Sadakane and E. Steckhan. Chem. Rev. 98, 219 (1998).

45. T. Yamase. Chem. Rev. 98, 307 (1998).

46. J. T. Rhule, C. L. Hill, D. A. Judd, R. F. Schinazi. Chem. Rev. 98, 327-357 (1998).

47. (a) M. T. Pope. In Mixed Valence Compounds, D. B. Brown (Ed.), D. Reidel, Dordrecht, p. 365 (1980); (b) M. T. Pope. Prog. Inorg. Chem. 39, 181 (1991).

48. (a) J. P. Gabriel and P. Davidson. Adv. Mater. 12, 9 (2000); (b) A. S. Sonin. Colloid J. 60, 129 (1998); (c) P. Davidson, P. Batail, J. P. Gabriel, J. Livage, C. Sanchez, C. Bourgaux. Prog. Polym. Sci. 22, 913 (1997).

49. D. G. Kurth, P. Lehmann, M. Schütte. Proc. Natl. Acad. Sci. 97, 5704 (2000).

50. Z. Khattari, E. Hatta, D. G. Kurth, T. M. Fischer. J. Chem. Phys. 115, 9923 (2001).

51. D. G. Kurth, N. Severin, J. P. Rabe. Angew. Chem., Int. Ed. Engl. 41, 3681 (2002).

52. A. Meister, G. Forster, A. F. Thünemann, D. G. Kurth. ChemPhysChem 4, 1095 (2003).

53. P. Lehmann, D. G. Kurth, G. Brezesinski, C. Symietz. Chem. Eur. J. 7, 1646 (2001).

54. H. Kuhn and D. Möbius. "Monolayer assemblies", in Physical Methods of Chemistry Series, Vol. IX, B. Rossiter and W. Baetzold (Eds.), pp. 375-542, John Wiley, New York (1993).

55. (a) D. G. Kurth, D. Volkmer, R. von Klitzing. In Thin Films - Polyelectrolyte Multilayers and Related Multicomposites, G. Decher and J. Schlenoff (Eds.), Chap. 14, pp. 393-426, Wiley-VCH, New York (2003); (b) M. Schütte, C. Stolle, D. G. Kurth. Supramol. Chem. 15, 549 (2003); (c) M. Schütte, D. G. Kurth, M. R. Linford, H. Cölfen, H. Möhwald. Angew. Chem. 110, 3058 (1998); Angew. Chem., Int. Ed. 37, 2891 (1998).

56. D. G. Kurth, A. Meister, A. F. Thünemann, G. Forster. Langmuir 19, 4055 (2003).

57. S. S. Sheiko and M. Möller. Chem. Rev. 101, 4099 (2001).

58. S. S. Sheiko. Adv. Polym. Sci. 151, 6 (2000).

59. J. P. Rabe and S. Buchholz. Science 253, 424 (1991).

60. N. Severin, J. P. Rabe, D. G. Kurth. J. Am. Chem. Soc. 126, 3696 (2004).

(C) 2004 IUPAC, Pure and Applied Chemistry 76, 1847-1867 
61. S. Valkama, T. Ruotsalainen, H. Kosonen, J. Ruokolainen, M. Torkkeli, R. Serimaa, G. ten Brinke, O. Ikkala. Macromolecules 36, 3986 (2003); S. Valkama, R. Maki-Ontto, M. Stamm, G. ten Brinke, O. Ikkala. Stud. Surf. Sci. Catal. 141, 371 (2002).

62. N. Kimizuka, N. Oda, T. Kunitake. Inorg. Chem. 39, 2684 (2000).

63. S. Valkama, O. Lehtonen, K. Lappalainen, H. Kosonen, P. Castro, T. Repo, M. Torkkeli, R. Serimaa, G. ten Brinke, M. Loskelä, O. Ikkala. Macromol. Rapid Commun. 24, 556 (2003).

64. C. M. Drain. Proc. Natl. Acad. Sci. USA 99, 5178 (2002).

65. (a) M. Washhold and M. Kanatzidis. Chem. Mater. 12, 2914-2923 (2000); (b) G. G. Jananer, A. D. Dobley, P. Y. Zavalij, M. S. Whittingham. Chem. Mater. 9, 647-649 (1997); (c) B. Donnoi, B. Heinrich, T. Gulik-Krzywicki, H. Delacroix, D. Guillon, D. W. Bruce. Chem. Mater. 9, 2951 (1997); (d) A. I. Smirnova and D. W. Bruce. Chem. Commun. 176-177 (2002).

66. (a) F. Bonhomme and M. G. Kantzidis. Chem. Mater. 10, 1153 (1998); (b) M. J. MacLachlan, N. Coombs, G. A. Ozin. Nature 397, 681 (1999); (c) M. J. MacLachlan, N. Coombs, R. L. Bedard, S. White, L. K. Thompson, G. A. Ozin. J. Am. Chem. Soc. 121, 12005 (1999); (d) F. Camerel, M. Antonietti, C. F. J. Faul. Chem. Eur. J. 9, 2160-2166 (2003); (e) J. Sayettat, L. M. Bull, J.-C. P. Gabriel, S. Jobic, F. Cameral, A.-M. Marie, M. Fourmigue, P. Batail, R. Brec, R.-L. Zinglebert. Angew. Chem., Int. Ed. Engl. 37, 1711 (1998).

67. K. Binnemans, L. Jongen, C. Gorlerr-Walrand, W. D’Olieslager, D. Hinz, G. Meyer. Eur. J. Inorg. Chem. 7, 1429-1436 (2000).

68. B. Messer, J. H. Song, M. Huang, Y. Wu, F. Kim, P. Yang. Adv. Mater. 12, 1526 (2000).

69. G. Schmid. Clusters and Colloids, VCH, Weinheim (1994).

70. P. Gouzerh and A. Proust. Chem. Rev. 98, 77 (1998).

71. J. H. Fendler. Nanoparticles and Nanostructured Films, VCH-Wiley, Weinheim (1998).

72. (a) M. Clemente-León, C. Mingotaud, B. Agricole, C. J. Gómez-García, E. Coronado, P. Delhaes. Angew. Chem., Int. Ed. Engl. 36, 1114 (1997); (b) C. G. Janauer, A. Dobley, J. D. Guo, P. Zavalij, M. S. Whittingham. Chem. Mater. 8, 2096 (1996); (c) A. Stein, M. Fendorf, T. P. Jarvie, K. T. Müller, A. J. Benesi, T. E. Mallouk. Chem. Mater. 7, 304 (1995).

73. D. G. Kurth, P. Lehmann, D. Volkmer, H. Cölfen, M. J. Koop, A. Müller, A. Du Chesne. Chem. Eur. J. 6, 385 (2000).

74. D. Volkmer, A. Du Chesne, D. G. Kurth, H. Schnablegger, P. Lehmann, M. J. Koop, A. Müller. J. Am. Chem. Soc. 122, 1995 (2000).

75. D. G. Kurth, P. Lehmann, D. Volkmer, A. Müller, D. Schwahn. J. Chem. Soc., Dalton Trans. 3989 (2000).

76. D. Volkmer, B. Bredenkötter, J. Tellenbröker, P. Kögerler, D. G. Kurth, P. Lehmann, H. Schnablegger, D. Schwahn, M. Piepenbrink, B. Krebs. J. Am. Chem. Soc. 124, 10489 (2002).

77. D. Braga. J. Chem. Soc., Dalton Trans. 3705 (2000).

78. I. Moriguchi, K. Orishikida, Y. Tokuyama, H. Watabe, S. Kagawa, Y. Teraoka. Chem. Mater. 13, 2430 (2001).

79. R. C. Chambers, E. J. O. Atkinson, D. McAdams, E. J. Hayden, D. J. A. Brown. Chem. Commun. 2456 (2003).

80. The molecular surface area of a single DODA cation as determined from the lamellar arrangement of DODA cations in the single-crystal structure of the compound DODA $\cdot \mathrm{Br}$ (monohydrate), CSD entry code CIYWOW20, is $56.7 \AA^{2}$ [K. Okuyama, Y. Soboi, N. Iijima, K. Hirabayashi, T. Kunitake, T. Kajiyama. Bull. Chem. Soc. Jpn. 61, 1485-1490 (1988)]. Empirical values for the molecular surface area of a single DODA cation have been frequently determined from the Langmuir isotherms of compressed DODA monolayers spread at the air-water interface. The reported values range from $60-100 \AA^{2} /$ DODA molecule, depending on the chemical nature of counter anions within the aqueous subphase. See: J. Marra. J. Phys. Chem. 90, 2145 (1986); M. Clemente-León, B. Agricole, C. Mingotaud, C. J. Gómez-García, E. Coronado, P. Delhaes. Langmuir 13, 2340 (1997). 
81. W. F. Bu, H. L. Fan, L. X. Wu, X. L. Hou, C. W. Hu, G. Zhang, X. Zhang. Langmuir 18, 6398 (2002).

82. W. F. Bu, L. X. Wu, X. L. Hou, X. L. Fan, C. W. Hu, X. Zhang. J. Colloid Interface Sci. 251, 120 (2002).

83. T. R. Zhang, R. Lu, H. Y. Zhang, P. C. Xue, W. Feng, X. L. Liu, B. Zhao, Y. Y. Zhao, T. J. Li, J. N. Yao. J. Mater. Chem. 13, 580 (2003).

84. S. Polarz, S. Smarsly, M. Antonietti. ChemPhysChem 2, 457 (2001).

85. D. G. Kurth, S. Liu, D. Volkmer. To be published.

86. C. D. Bain, E. B. Troughton, Y.-T. Tao, J. Evall, G. M. Whitesides, R. G. Nuzzo. J. Am. Chem. Soc. 11, 321 (1989).

87. Z. Horvölgyi, G. Medveczky, M. Zrinyi. Colloid Polym. Sci. 271, 396 (1993); (b) Z. Horvölgyi, S. Nemeth, J. H. Fendler. Coll. Surf. A: Physicochem. Eng. Asp. 71, 327 (1993).

88. S. Liu, D. Volkmer, D. G. Kurth. Unpublished results.

89. S. Mann, R. B. Frankel, R. P. Blakemor. Nature 310, 405 (1984).

90. P. Lianos and J. K. Thomas. Chem. Phys. Lett. 125, 299 (1986).

91. A. Ulman. An Introduction to Ultrathin Organic Films from Langmuir-Blodgett to Self-assembly, Academic Press, Boston (1991).

92. L. Addadi and S. Weiner. Angew. Chem., Int. Ed. Engl. 31, 153 (1992).

93. S. Weiner and L. Addadi. J. Mater. Chem. 7, 689 (1997).

94. G. Xu, N. Yao, I. A. Aksay, J. T. Groves. J. Am. Chem. Soc. 120, 11977 (1998).

95. S. Forster and M. Antonietti. Adv. Mater. 10, 195 (1998).

96. T. Kato and T. Amamiya. Chem. Lett. 199 (1999).

97. J. J. Stohoff and C. A. Mirkin. Chem. Rev. 99, 1849 (1999).

98. A. K. Boal, F. Ilhan, J. E. Derouchey, T. Thum-Albrecht, T. P. Russell, V. M. Rotello. Nature 404, 746 (2000).

99. J. H. Fendler and F. C. Meldrum. Adv. Mater. 7, 607 (1995).

100. (a) G. Schmid. Chem. Rev. 92, 1709 (1992); (b) M. Brust, J. Fink, D. Bethell, D. J. Schiffrin, C. Kiely. Chem. Commun. 1655 (1995); (c) M. J. Hostetler and R. W. Murray. Curr. Opin. Colloid Interface Sci. 2, 42 (1997).

101. (a) M. T. Reetz, M. Winter, B. Tesche. Chem. Commun. 147 (1997); (b) M. T. Reetz, W. Helbig, A. A. Quaiser, U. Stimming, N. Breuer, R. Vogel. Science 267, 367 (1995); (c) U. Schon and U. Simon. Colloid Polym. Sci. 273, 101 (1995).

102. L. Shen, P. E. Laibinis, T. A. Hatton. Langmuir 15, 447 (1999).

103. (a) M. Gao, B. Richter, S. Kirstein. Synth. Met. 102, 1213 (1997); (b) M. Gao, B. Richter, S. Kirstein. Adv. Mater. 9, 802 (1997).

104. D. G. Kurth, P. Lehmann, C. Lesser. Chem. Commun. 949 (2000).

105. G. Mériguet, E. Dubois, R. Perzynski. J. Colloid Interface Sci. 267, 78 (2003).

106. G. Decher and J. B. Schlemoff (Eds.). Multilayer Thin Film, Wiley-VCH, Weinheim (2003). 